\title{
Gut/brain axis and the microbiota
}

\author{
Emeran A. Mayer, ${ }^{1,2,3,4}$ Kirsten Tillisch, ${ }^{1,2,5}$ and Arpana Gupta ${ }^{1,2}$ \\ ${ }^{1}$ Oppenheimer Center for Neurobiology of Stress, Division of Digestive Diseases, ${ }^{2}$ Department of Medicine, ${ }^{3}$ Department of Physiology, and ${ }^{4}$ Department of Psychiatry, \\ David Geffen School of Medicine at UCLA, Los Angeles, California, USA. 5Division of Integrative Medicine, Greater Los Angeles VA Healthcare System, Los Angeles, California, USA.
}

\begin{abstract}
Tremendous progress has been made in characterizing the bidirectional interactions between the central nervous system, the enteric nervous system, and the gastrointestinal tract. A series of provocative preclinical studies have suggested a prominent role for the gut microbiota in these gut-brain interactions. Based on studies using rodents raised in a germ-free environment, the gut microbiota appears to influence the development of emotional behavior, stress- and pain-modulation systems, and brain neurotransmitter systems. Additionally, microbiota perturbations by probiotics and antibiotics exert modulatory effects on some of these measures in adult animals. Current evidence suggests that multiple mechanisms, including endocrine and neurocrine pathways, may be involved in gut microbiota-to-brain signaling and that the brain can in turn alter microbial composition and behavior via the autonomic nervous system. Limited information is available on how these findings may translate to healthy humans or to disease states involving the brain or the gut/brain axis. Future research needs to focus on confirming that the rodent findings are translatable to human physiology and to diseases such as irritable bowel syndrome, autism, anxiety, depression, and Parkinson's disease.
\end{abstract}

\section{Introduction}

Alterations in bidirectional brain-gut microbiota interactions are believed to be involved in the pathogenesis of well-known braingut disorders such as irritable bowel syndrome (IBS) and related functional gastrointestinal (GI) disorders $(1,2)$ and have more recently been implicated as a possible mechanism in the pathophysiology of several brain disorders including autism spectrum disorders (ASDs) $(3,4)$, Parkinson's disease (5), disorders of mood and affect $(3,6)$, and chronic pain $(7)$. However, there is considerable controversy over the magnitude as well as the sites, pathways, and molecular mechanisms within the gut/brain axis that are responsible for these alterations. The intestinal microbiota and its metabolites have been shown to be involved in modulating GI functions, given their ability to affect intestinal permeability (8-11), mucosal immune function (9-14), intestinal motility (15) and sensitivity $(14,16)$, and activity in the enteric nervous system (ENS) (reviewed in ref. 17). Additionally, preclinical evidence suggests that the microbiota and its metabolites are likely to be involved in modulating behaviors and brain processes, including stress responsiveness (reviewed in ref. 18), emotional behavior (reviewed in ref. 19), pain modulation (reviewed in refs. 3, 20), ingestive behavior (reviewed in ref. 21), and brain biochemistry (reviewed in ref. 22).

To date, there is limited high-quality evidence regarding alterations of microbial ecology or production of microbial-derived metabolic products in human patients with brain or gutbrain disorders (11). For example, there is inconclusive evidence from human studies regarding the beneficial effects of manipulating the microbiota with prebiotics and antibiotics in patients with IBS, even though meta-analyses suggest a small therapeutic effect

Conflict of interest: The authors have declared that no conflict of interest exists. Reference information: J Clin Invest. 2015;125(3):926-938. doi:10.1172/JCI76304. for probiotics (reviewed in refs. 23, 24). Furthermore, it is not clear whether alterations observed in the microbiota of patients with these disorders arise from primary alterations at the gut microbial interface (bottom-up effects) and/or changes in brain-to-gut signaling (top-down effects).

Despite the limited clinical evidence, a large and growing number of review articles have appeared in the literature $(3,5$, 25-27), extrapolating the preclinical findings to human diseases and even to human brain development (28). However, other than a series of case reports on the development of psychotic symptoms following broad-spectrum antibiotic intake $(29,30)$, there is limited clinical evidence that acute alteration of the intestinal microbiota has an effect on clinical symptoms (5, 31-34).

This article critically reviews the current preclinical literature, explores the current evidence in humans consistent with the preclinical findings, and identifies translational research areas required to identify a role of the gut microbiota in modulating the brain and the gut/brain axis.

\section{Gut microbiota effects on the brain: preclinical evidence}

Several experimental approaches have been used to study the modulatory effect of gut microbiota on gut-brain interactions, including gut microbial manipulation with antibiotics (35), fecal microbial transplantation $(35,36)$, and germ-free (GF) animal models (ref. 37 and Figure 1). Despite the limitations of these approaches, considerable progress has been made from the first seminal observation by Sudo and colleagues in experimental animals that the absence of a normal gut microbiota can have significant effects on adult stress responsiveness and that these alterations can be partially reversed by colonization of the gut (37). A range of microbiota-related effects have been reported in relation to anxiety-like behavior (38-45), depression-like behavior (42, 45-48), nociceptive responses (7, 49-53), stress responsiveness 


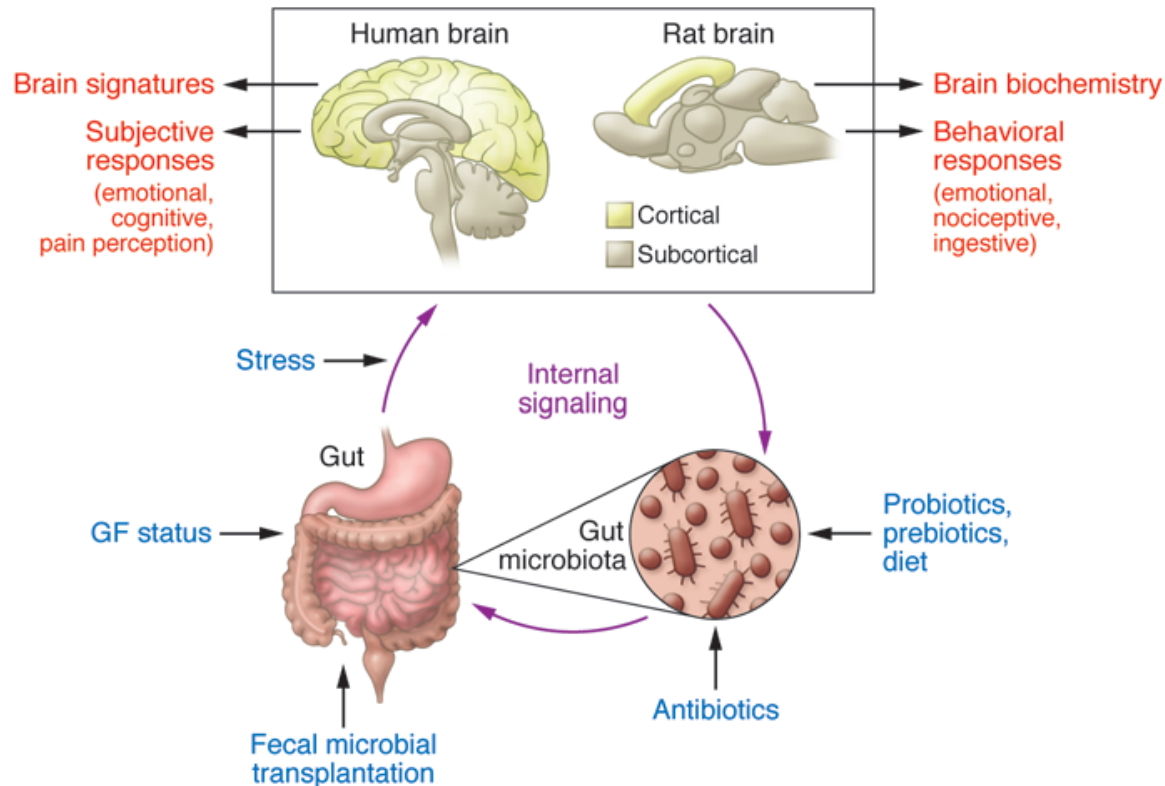

Figure 1. Experimental paradigms and readouts of the gut microbiota/brain axis in humans and rodents. Preclinical studies have used a range of experimental paradigms to study the role of the gut microbiota in gut-brain interactions (blue text). Readouts used in these preclinical studies are listed to the right of the rat brain. Except for GF status, the same experimental paradigms can be used in human studies. In contrast to rodents, subjective responses and structural and functional brain imaging are suitable readouts in human subjects. Notice the considerable difference between the relative proportion of cortical and subcortical structures between the human and rodent brain.
$(42,43)$, feeding behavior, taste preferences, and metabolic consequences (refs. 54-56 and summarized in Tables 1, 2, 3, and 4).

The GF model has several limitations that suggest that researchers should be cautious when extrapolating the findings to humans. GF animals are born in aseptic conditions, which may include removal from the mother by Cesarean section and immediate transfer of the newborn to an isolator, where all incoming air, food, and water are sterilized. There is a wide range of differences in brain (and gut) biochemistry $(39,57)$; hypothalamic/pituitary/ adrenal (HPA) axis responses (37); and affective (38-48), social $(48,58-60)$, metabolic function, and ingestive behaviors (54-56) between GF animals and control animals that have normal or pathogen-free flora and were reared by normally colonized mothers $(39,40)$. Thus, observed brain and behavioral changes could be mediated by the lack of gut microbiota directly or indirectly through one or several of the non-brain-related alterations. Recent evidence suggests that the intrauterine environment is not sterile (61), and one may even speculate that maternal gut microbial metabolites originating from the maternal gut microbiome may have an influence on fetal brain development. Furthermore, as GF pups are raised by GF mothers, the absence of fecal microbes may interfere with well-characterized maternal behaviors, such as arched-back nursing and anogenital licking. These behaviors have been associated with epigenetic changes at stress-related genes (62) that regulate the development of systems within the CNS (63). However, in one study where maternal behavior was analyzed on the second and third days postpartum, no effect of the GF status on such maternal behaviors was observed (37). Altered signaling of the cecum to the brain, secondary to the massive cecal dilation associated with this model, could alter development of brain regions processing such input. GF mice are leaner than control animals, despite consuming more calories $(64,65)$. Metabolic changes secondary to the loss of an important source of calories (gut microbiota-generated short-chain fatty acids [SCFAs]) for the developing organism may affect brain development and alter the activity of brain circuits involved in feeding behavior and metabolism. Finally, the recently reported alterations in the permeability of the blood-brain barrier in GF mice is likely to result in significantly altered access of gut microbial metabolites to the brain (66). Despite the extensive remodeling of biological systems in the GF animal, the fact that some observed behaviors and brain changes could be reversed by reconstitution of pathogen-free microbiota (conventionalization) validates some of the conclusions drawn. Nevertheless, as the GF animal has no counterpart in human brain development, premature conclusions about the relevance of these findings to humans should be avoided. Broad-spectrum antibiotics have well-documented transient effects on the composition and diversity of fecal microbiota (35) even though the effects on mucosa-associated microbial communities are not known. Furthermore, antibiotic-related effects may be mediated by the associated mucosal immune activation reported with such interventions (67).

Of reports published since 2010 using different strains of mice and rats, different strains of probiotics, and different experimental paradigms (ref. 22 and Figure 1), a range of effects of gut microbial modulation was reported on emotional behavior (38-43, 48, $68-70)$, learning and memory $(42,71,72)$, social interactions $(48$, $58,73)$, and ingestive behaviors (55). Results of these studies are summarized in Tables 1-4.

Emotional behavior. When viewed together, reported findings demonstrate an increase in emotional behavior associated with infection/infestation with pathogens (38-40, 70); a reduction of basal or induced anxiety-like behavior in animals with normal gut microbiota, resulting from different, orally administered probiotics $(41-43,47,52,53,56,74,75)$; and both reduced $(38-40,70)$ and increased anxiety $(72)$ in rodents that have been raised in the absence of a gut microbiota. A reduction in depression-like behaviors was observed in different rodent models with normal gut microbiota, following administration of a probiotic $(42,48)$. Depression-like behavior in these models was induced by maternal separation (47) and experimental myocardial infarction (MI) (48). 


\section{Table 1. Effects of gut microbial modulation on rodent emotional behavior}

\begin{tabular}{|c|c|c|c|c|}
\hline $\begin{array}{l}\text { Reference } \\
\text { Emotional }\end{array}$ & $\begin{array}{l}\text { Sample } \\
\text { behaviors }\end{array}$ & Method & Biological readouts & Behavioral readouts \\
\hline $\begin{array}{l}\text { Neufeld et } \\
\text { al. (40) }\end{array}$ & $\begin{array}{l}\text { Adult female } \\
\text { Swiss-Webster } \\
\text { mice }\end{array}$ & $\begin{array}{l}\text { GF vs. conventionally raised SPF mice: } \\
\text { Locomotor activity in activity chambers } \\
\text { Elevated plus maze test } \\
\text { Serum corticosterone levels } \\
\text { Cene expression }\end{array}$ & $\begin{array}{l}\text { In CF mice: } \\
\text { Total distance traveled in activity chambers did not differ } \\
\text { Increased open-arm exploration in plus maze test } \\
\text { Increased concentrations of corticosterone levels } \\
\text { Decreased NMDA subunit NR2B mRNA expression in central amygdala } \\
\text { Decreased BDNF expression in dentate gyrus layer of hippocampus } \\
\text { Decreased 5-HT1A expression in dentate gyrus layer of hippocampus }\end{array}$ & Decreased anxiety-like behavior \\
\hline $\begin{array}{l}\text { Bercik et al. } \\
\text { (41) }\end{array}$ & $\begin{array}{l}\text { Adult male AKR } \\
\text { mice }\end{array}$ & $\begin{array}{l}\text { Mice with normal flora: } \\
\text { Chronic DSS colitis } \\
\text { B. Iongum NCC3001 on the 3rd cycle of DSS } \\
\text { Step-down and light preference tests } \\
\text { BDNF mRNA measured in neuroblastoma } \\
\text { SH-SY5Y cells }\end{array}$ & $\begin{array}{l}\text { Chronic colitis was associated with increased anxiety-like behavior } \\
\text { Anxiety-like behavior was normalized by B. longum NCC3001 } \\
\text { treatment } \\
\text { NCC3001 treatment had no effect on BDNF mRNA expression in } \\
\text { neuroblastoma SH-SY5Y cells, but decreased excitability of enteric } \\
\text { neurons }\end{array}$ & $\begin{array}{c}\text { Increased anxiety-like behavior following colitis, } \\
\text { which was normalized by B. longum NCC3001 } \\
\text { treatment }\end{array}$ \\
\hline $\begin{array}{l}\text { Bravo et al. } \\
\text { (42) }\end{array}$ & $\begin{array}{l}\text { Adult male } \\
\text { BALB/c mice }\end{array}$ & $\begin{array}{l}\text { Broth gavage with L. rhamnosus (JB-1) or } \\
\text { without bacteria } \\
\text { Stress-induced hyperthermia } \\
\text { Elevated plus maze test } \\
\text { Fear-conditioning paradigm } \\
\text { Open-field paradigm } \\
\text { Forced swim test }\end{array}$ & 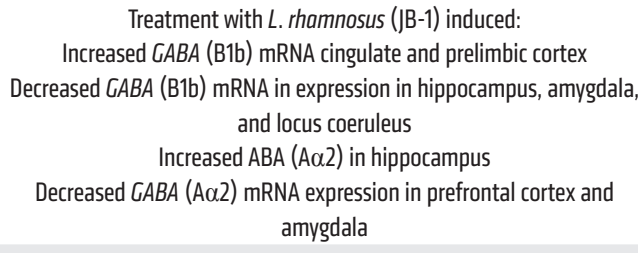 & $\begin{array}{l}\text { Mice treated with L. rhamnosus (JB-1) showed } \\
\text { decreased anxiety- and depression-like behaviors }\end{array}$ \\
\hline $\begin{array}{l}\text { Desbonnet, } \\
\text { et al. (47) }\end{array}$ & $\begin{array}{l}\text { Adult pregnant } \\
\text { Sprague-Dawley } \\
\text { dams and } \\
\text { offspring }\end{array}$ & $\begin{array}{c}\text { Mice underwent MS } \\
\text { Administration of } B \text {. infantis } \\
\text { Treatment with citalopram hydrobromide } \\
\text { Forced swim test } \\
\text { Measurement of cytokine concentrations } \\
\text { in whole blood samples, monoamine levels } \\
\text { in brain, central and peripheral HPA axis } \\
\text { indicators }\end{array}$ & $\begin{array}{l}\text { MS mice had decreased NA content in the brain, increased peripheral } \\
\text { IL- } 6 \text { release, and increased amygdala CRF mRNA levels } \\
\text { In MS mice, B. infantis treatment resulted in normalization of the } \\
\text { immune response and restoration of basal NA concentrations in the } \\
\text { brainstem }\end{array}$ & $\begin{array}{l}\text { MS mice had decreased swim behavior and } \\
\text { increased immobility in forced swim test } \\
\text { Mice treated with } B \text {. infantis had decreased } \\
\text { anxiety-like behavior }\end{array}$ \\
\hline $\begin{array}{l}\text { Crumeyrolle- } \\
\text { Arias et al. } \\
\text { (44) }\end{array}$ & $\begin{array}{l}\text { - Adult female GF } \\
\text { and pregnant } \\
\text { SPF F344 rats }\end{array}$ & $\begin{array}{c}\text { Open field test } \\
\text { Social interactions } \\
\text { Serum corticosterone (CRF) concentrations }\end{array}$ & $\begin{array}{c}\text { GF rats exhibited: } \\
\text { Increased CRF mRNA in hypothalamus } \\
\text { Decreased GR mRNA expression in hippocampus } \\
\text { and striatum } \\
\text { Decreased dopaminergic turnover rate in hippocampus, frontal cortex, } \\
\text { Increased CRF levels after the open field stress test }\end{array}$ & $\begin{array}{l}\text { Absence of gut microbiota in F344 rats increased } \\
\text { reactivity to stress and anxiety-like behavior, and } \\
\text { reduced social interactions }\end{array}$ \\
\hline $\begin{array}{l}\text { Savignac et } \\
\text { al. (45) }\end{array}$ & $\begin{array}{l}\text { Adult male } \\
\text { BALB/cOlaHsd } \\
\text { mice }\end{array}$ & $\begin{array}{l}\text { Administration of } B \text {. longum 1714, } B \text {. breve } \\
\text { 1205, antidepressant escitalopram, or vehicle } \\
\text { Stress-induced hypothermia FITC-dextran } \\
\text { Tests: marble burying, elevated plus maze, } \\
\text { open field, tail suspension, forced swim }\end{array}$ & No group differences in corticosterone levels & $\begin{array}{l}\text { Bifidobacteria strains caused decreased anxiety- } \\
\text { like behavior in marble-burying test } \\
\text { B. Iongum } 1714 \text { associated with reduced stress- } \\
\text { induced hyperthermia } \\
\text { B. Iongum } 1714 \text { associated with decreased } \\
\text { depression-like behavior in tail suspension test } \\
\text { B. breve } 1205 \text { associated with decreased anxiety- } \\
\text { like behavior in elevated plus maze } \\
\text { Escitalopram associated with decreased anxiety- } \\
\text { like behavior in marble burying test }\end{array}$ \\
\hline
\end{tabular}

CRF, corticotrophin-releasing factor; GR, glucocorticoid receptor; 5-HT1A, 5-hydroxytryptamine 1A; MI, myocardial infarction; MS, maternal separation; NA, noradrenaline; SPF, specific pathogen free. 
Table 2. Effects of gut microbial modulation on learning and memory in rodents

\begin{tabular}{|c|c|c|c|c|}
\hline $\begin{array}{l}\text { Reference } \\
\text { Learning and }\end{array}$ & $\begin{array}{l}\text { Sample } \\
\text { d memory }\end{array}$ & Method & Biological readouts & Behavioral readouts \\
\hline $\begin{array}{l}\text { Davari et al. } \\
\text { (71) }\end{array}$ & Adult male Wistar rats & $\begin{array}{l}\text { Control and diabetic rats received normal } \\
\text { regimen or probiotic supplementation (mixture } \\
\text { of } L \text {. acidophilus, } B \text {. lactis and } L \text {. fermentum) } \\
\text { Streptozocin-induced diabetes model } \\
\text { Morris water maze } \\
\text { Recording of EPSPs in CA1 area of the } \\
\text { hippocampus } \\
\text { Measurements: serum levels of glucose, insulin, } \\
\text { SOD, and 8-OHDG }\end{array}$ & $\begin{array}{l}\text { Probiotic supplementation was associated with: } \\
\text { Improved spatial memory and restored hippocampal } \\
\text { LTP in diabetes model } \\
\text { Increased levels of SOD } \\
\text { Increased insulin and decreased glucose levels } \\
\text { Decreased 8-OHDG factor } \\
\text { Increased synaptic transmission in hippocampus }\end{array}$ & $\begin{array}{l}\text { Probiotic mixture caused improved } \\
\text { learning and memory in diabetes model }\end{array}$ \\
\hline $\begin{array}{l}\text { Gareau et al. } \\
\text { (72) }\end{array}$ & $\begin{array}{c}\text { Adult female Swiss- } \\
\text { Webster and adult female } \\
\text { C57BL/ } 6 \text { mice }\end{array}$ & $\begin{array}{c}\text { GF vs. SPF status } \\
\text { Infection with Citrobacter rodentium } \\
\text { Tests: } \\
\text { Water avoidance stress test, novel object test, } \\
\text { T-maze test (examine natural tendency to } \\
\text { explore novel environments), light-dark box } \\
\text { test }\end{array}$ & Not applicable & $\begin{array}{l}\text { GF mice (with or without stress) showed } \\
\text { reduced memory compared with controls } \\
\text { C57BL/6 mice treated with C. rodentium } \\
\text { showed no behavioral abnormalities, } \\
\text { improved memory compared with } \\
\text { controls, and reduced stress-induced } \\
\text { memory loss }\end{array}$ \\
\hline $\begin{array}{l}\text { Diaz Heijtz } \\
\text { et al. (39) }\end{array}$ & Adult male NMRI mice & $\begin{array}{l}\text { GF mice vs. conventionally raised SPF mice } \\
\text { Measurements: } \\
\text { DA receptor (D1 and D2) expression } \\
\text { DARPP-32 expression }\end{array}$ & $\begin{array}{l}\text { GF mice had: } \\
\text { Increased DA D1 receptor mRNA levels in hippocampus } \\
\text { Decreased DA D1 receptor in striatum and nucleus } \\
\text { accumbens } \\
\text { No significant differences in DA D2 and DARPP-32 }\end{array}$ & Reduced cognitive function in GF group \\
\hline $\begin{array}{l}\text { Bravo et al. } \\
(42)\end{array}$ & Adult male BALB/c mice & $\begin{array}{c}\text { Broth gavage with L. rhamnosus (JB-1) or } \\
\text { without bacteria } \\
\text { Stress-induced hyperthermia } \\
\text { Elevated plus maze } \\
\text { Fear-conditioning paradigm } \\
\text { Open-field paradigm } \\
\text { Forced swim test }\end{array}$ & $\begin{array}{l}\text { With L. rhamnosus (JB-1) treatment: } \\
\text { Region-dependent alterations in CABA (B1b) } \\
\text { mRNA in the brain: expression increased in cortical } \\
\text { regions (cingulate and prelimbic), but decreased in } \\
\text { hippocampus, amygdala, and locus coeruleus } \\
\text { GABA (A } 2 \text { 2) mRNA expression decreased in prefrontal } \\
\text { cortex and amygdala, but increased in hippocampus }\end{array}$ & $\begin{array}{l}\text { L. rhamnosus (JB-1) treatment reduced } \\
\text { cognitive abilities (measured by } \\
\text { extinguishing fear conditioning) }\end{array}$ \\
\hline
\end{tabular}

DA, dopamine; EPSP, potentiated excitatory postsynaptic potential; LTP, long-term potentiation; 8-OHDG; 8-hydroxy-2'-deoxyguanosine; SOD, superoxide dismutase.

Learning and memory. While improvement of impaired memory function by probiotics was observed in a rodent model of diabetes (71), several studies showed a worsening with exposure to a pathogen (72), GF status (39), and administration of a probiotic (42).

Social interactions and ASD-like behaviors. Gut microbiota status was found to reduce social interactions in GF mice (58), and probiotics improved social interactions in a post-MI rat model (48, 58, 73). Gut microbiota-associated behavioral changes were reported in different ASD mouse models using valproic acid administration (59) or maternal infection (60); in the latter instance, treatment with the probiotic Bacteroides fragilis had a beneficial effect on some of the behavioral abnormalities (60).

Ingestive behavior. A limited number of studies suggest that gut microbial composition can influence ingestive behavior $(54,55,57)$. Some of these effects are likely mediated by significant alterations in intestinal taste receptor, fatty acid receptors, intestinal transport mechanisms, and changes in the release of satiety hormones.

HPA axis responsiveness. Increased basal or stimulated HPA axis activity (measured as blood corticosterone or ACTH levels) was reported in GF Swiss-Webster and BALB/c mice $(38,40,72)$, while a probiotic-induced reduction of corticosterone levels was observed in normal mice (42). The association of increased HPA axis responses and reduced anxiety-like behaviors observed in several of the studies performed in GF mice suggests that hypo- thalamic (HPA axis) and nonhypothalamic (anxiety-like behavior) components of central stress circuits may be affected differentially by the GF conditions, depending on species and mouse strain, a response pattern not seen in the majority of anxiety models in which these two components of the stress response are generally congruent. These findings suggest that the increased HPA axis activity in GF animals may represent a response of the organism to the loss of microbiota-related energy sources. However, two studies have reported evidence for both increased anxiety-like behavior and HPA axis hyperresponsiveness in BALB/c mice (76) and in F344 male rats (44).

Epithelial permeability. Alterations in gut epithelial permeability have been described in IBS (77) and in some patients with autism and schizophrenia (78). Gut microbiota and probiotics play an important modulatory role on intestinal barrier function $(79,80)$. Recent evidence has shown that the probiotic B. fragilis normalizes increased intestinal epithelial permeability in an ASD mouse model (60).

Brain-signaling systems. Several studies showed reduced expression of brain-derived neurotrophic factor (BDNF) in the brains of GF animals (primarily in hippocampus) $(35,38,39,72)$ and increased BDNF expression in infection models (70). Other reported regional changes in receptor expression include GABA receptor $A$ and $B$ subunits (which mediate the effects of the major 


\section{Table 3. Effects of gut microbial modulation on rodent social and autism-like behaviors and ingestive behaviors}

\section{Reference Sample}

Social and autism-like behaviors

Desbonnet Adolescent and adult Conventionally colonized mice vs. CF mice

et al. (58) male GF mice that underwent bacterial colonization after weaning

Three-chambered sociability test
Biological readouts

Not applicable

Increased intestinal permeability in MI rats

Arseneualt- Adult male Sprague- MI induced in anesthetized rats treated with Breard et al. Dawley rats L. helveticus R0052 and B. longum R0175) or (48) vehicle (maltodextrin) Forced swim test

Passive avoidance step-down test Intestinal permeability (FITC-dextran) al. (59) females and their exposure to valproic acid in pregnant females
Intestinal permeability reversed/restored by probiotics de Theije et Pregnant BALB/c Autism-like behavior induced by prenatal male and female Pups were exposed to the social behavior offspring test after weaning Inflammatory markers measured in brain and intestinal tissue

Pups exposed to valproic acid demonstrated: Decreased social behavior

Increased expression of neuroinflammatory markers in male and female brains

Males had epithelial cell loss and neutrophil infiltration in intestinal tract

Male pups had decreased serotonin levels in prefrontal cortex, amygdala, and small intestine

Reduced serotonin levels in brain and intestine in a sexspecific manner

Hsiao et al. Pregnant C57BL/6N MIA model was used to evaluate the effect of (60) mice and offspring maternal infection on autism-like behaviors in offspring

\section{Ingestive behavior}

Duca et al. Adult male [57BL/6]
(54) $\quad$ mice

GF mice vs. NORM mice:

Preference for and acceptance of fat emulsions

Changes in lingual and intestinal fatty acid receptors, intestinal peptide content, and plasma levels of gut peptides

\section{Vijay-Kumar Adult male and} et al. (55) female [57BL/6 mice
Gut microbiota from TLR5-deficient mice was transferred to WT GF mice

\section{specific manner
In MIA offspring:}

Porphyromonadaceae, prevotellaceae, unclassified bacteriodales, and lachnospiriceae were more abundant Significant alterations in $8 \%$ of all serum metabolites, including increased 4EPS

In control animals, administration of 4EPS caused autism-like behaviors

B. fragilis treatment of MIA offspring led to significant restoration in relative abundance of bacteroidia and clostridia of the family lachnospiraceae

B. fragilis treatment of MIA offspring restored serum metabolite levels, especially 4EPS
4EPS, 4-ethylphenylsulfate; MIA, maternal immune activation. Increased lingual CD36 and decreased intestinal expression of fatty acid receptors GPR40, GPR41, GPR43, and GPR120 and satiety peptides CCK, PYY, and GLP-1

Number of enteroendocrine cells decreased in ileum and increased in colon

Reduced levels of circulating leptin and ghrelin, altered plasma lipid metabolic markers indicative of energy deficits Compared with GF mice, TLR5-deficient mice exhibited hyperlipidemia, insulin resistance, metabolic syndrome, adiposity

\section{Behavioral readouts}

Compared with conventionally colonized mice, GF mice showed:

Increased social avoidance

Reduced preference for social novelty Decreased time engaged in social investigation

Increased time engaged in repetitive self-grooming behavior during social interaction

Behaviors were normalized following bacterial colonization of GF mice

$\mathrm{Ml}$ rats displayed reduced social interaction and performance in forced swim and step-down tests Probiotics reversed behavioral effects of MI

Pups exposed to valproic acid showed reduced social behavior

MIA offspring showed ASD-like behaviors Treatment of MIA offspring with $B$. fragilis ameliorated defects in communicative, stereotypic anxiety and sensorimotor behaviors and did not affect social behavior deficits
CF mice showed increased preference for and caloric intake of fats
TLR5-deficient mice showed hyperphagia, which was transferable to GF mice by fecal transplant




\section{Table 4. Effects of gut microbial modulation on rodent HPA axis and stress responsiveness and epithelial permeability}

\section{Reference Sample \\ HPA axis and stress responsiveness \\ Gareau et al. Adult female Swiss- \\ (72) Webster and adult \\ female [57BL/6 mice

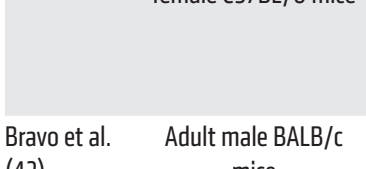 \\ (42) mice}

Method
GF vs. conventionally raised SPF mice infected with C. rodentium

Tests: water avoidance stress test, novel object test, T-maze test (examine natural tendency to explore novel environments), light-dark box test CRF levels were measured

Broth gavage with L. rhamnosus (JB-1) or without bacteria

Stress-induced hyperthermia Elevated plus maze

Fear conditioning paradigm Open field paradigm

Forced swim test
Biological readouts

C. rodentium infection resulted in decreased CRF levels, colonic epithelial cell hyperplasia, and colonic Ifng mRNA

Treatment with L. rhamnosus (JB-1) induced: Decreased stress-induced corticosterone response $\mathrm{CABA}$ (B1b) receptor mRNA expression increased in cortical regions (cingulate and prelimbic) CABA (B1b) receptor mRNA expression decreased in subcortical regions (hippocampus, amygdala and locus coeruleus)

CABA $(A \alpha 2)$ mRNA expression decreased in prefronta cortex and amygdala but increased in hippocampus

Clarke et al. Adult male and female
(38) Swiss-Webster mice

Crumeyrolle- Adult female GF and

Arias et al. pregnant SPF F344 rats (44)

Neufeld et Adult female Swiss-

al. (40) Webster mice
GF vs. SPF mice

Light-dark box test

Stress-induced corticosterone (novel environment)

\section{GF mice had:}

Increased corticosterone concentrations following acute stressor in males and females Increased 5-hydroxytryptamine and 5-hydroxyindoleacetic acid levels in hippocampus Increased concentrations of tryptophan (serotonin precursor) in males

Decreased BDNF levels in the hippocampus

Compared with SPF mice, GF mice had: Increased corticosterone levels

Measurements: locomotor activity, CRF levels, gene expression Elevated plus maze test

\section{GF vs. SPF mice \\ Open-field test \\ Social interactions \\ CRF levels}

Increased open arm exploration in elevated plus maze test

Decreased NMDA receptor subunit NR2B mRNA expression in central amygdala

Decreased BDNF expression in dentate gyrus layer Decreased 5-HT1A expression in dentate gyrus layer Compared with SPF F344 rats, GF rats exhibited: Increased CRF levels after open-field stress test Increased CRF mRNA in hypothalamus

Decreased GR mRNA expression in hippocampus Reduced dopaminergic turnover rate in hippocampus, frontal cortex, and striatum
Behavioral readouts

Poorer memory in GF mice (with or without stress)

Poorer memory in C57BL/ 6 mice infected with $C$. rodentium when exposed to stress

\section{Mice treated with L. rhamnosus (JB-1) showed reduced anxiety- and depression-like behaviors}

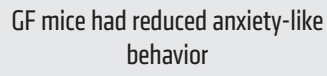
behavior

GF mice had reduced anxiety-like behavior

GF rats exhibited increased reactivity to stress and anxiety-like behavior and fewer social interactions

\section{Epithelial permeability}

\begin{tabular}{|c|c|c|}
\hline $\begin{array}{l}\text { Hsiao et al. } \\
\text { (60) }\end{array}$ & $\begin{array}{l}\text { Adult pregnant } \\
\text { C57BL/6N mice and } \\
\text { offspring }\end{array}$ & $\begin{array}{c}\text { MIA model was used to link maternal infection } \\
\text { to increased autism risk in offspring } \\
\text { Measurement: intestinal permeability before } \\
\text { and after } B \text {. fragilis }\end{array}$ \\
\hline
\end{tabular}

Arseneualt- Adult male SpragueBreard et al. Dawley rats

(48)
MI was induced in anesthetized rats Rats received either $L$. helveticus $\mathrm{R} 0052$ and

B. longum R0175 or vehicle (maltodextrin) Intestinal permeability evaluated by FITC-dextran
MIA offspring had GI barrier defects, as reflected by increased translocation of FITC-dextran across the intestinal epithelium, into the circulation B. fragilis treatment of MIA offspring: Improved GI barrier defect

Significantly restored relative abundance of bacteroidia and clostridia of the family lachnospiraceae

Restored serum metabolites (especially 4EPS) to control levels

Increased intestinal permeability in MI rats Probiotics reversed/restored intestinal permeabilit/

\section{MIA offspring showed ASD-like behaviors}

$B$. fragilis treatment of MIA offspring: Ameliorated defects in communicative, stereotypic anxiety, and sensorimotor behaviors

Did not affect social behavior deficits
Ml rats displayed fewer social interactions and poorer performance in forced swim and step-down tests
Probiotics reversed behavioral effects of $\mathrm{MI}$ inhibitory neurotransmitter in the brain) (42), NMDA receptor subunits (which mediate some of the effects of the excitatory neurotransmitter glutamate) (70), serotonin 1A (40), and tryptophan and tryptophan metabolite levels (38). Some of these changes in neuroreceptor expression were correlated with altered emotional behaviors (39, 40, 42, 70), implying an interaction between microbial composition and behavior. Results of studies in which such measures were assessed are summarized in Tables $1-4$. 


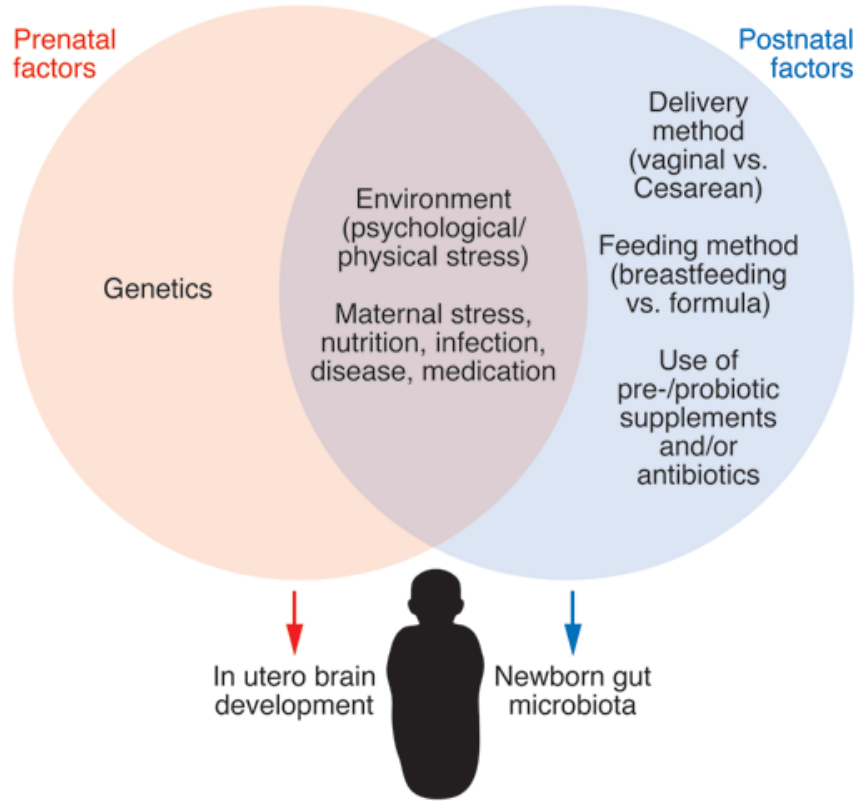

Figure 2. Influences on the gut microbiota/brain axis in the perinatal period. Multiple factors affecting the maternal gut microbiota can influence brain development in utero via microbial metabolites, drugderived chemical metabolites, and inflammatory changes. Postnatally, the newborn's microbiota is strongly influenced by the maternal vaginal or skin-derived microbiota (depending on the mode of delivery) during birth and by various nutritional factors (breast vs. infant formula feeding). Modified with permission from Trends in Molecular Medicine (139).

\section{Role of gut microbiota in brain development}

Given the important role of perinatal influences on the developing nervous system and the well-documented effects of adverse early life influences on the gut/brain axis, there is a strong rationale to implicate the gut microbiota in these processes (refs. 22, 81, and Figure 2). In animal models, prenatal and postnatal stress can alter the composition and total biomass of the enteric microbiota $(82,83)$. The majority of studies have compared adult behaviors, brain findings, and physiological responses, such as activation of the HPA axis, between animals born into and raised in a GF environment and animals raised in a laboratory cage environment. A smaller number of studies have reported data showing a role of gut microbiota in the effect of early adverse life events on adult behavior. Support for such long-lasting consequences for adult phenotypes of early life perturbations of the gut microbiota comes from two recent studies of the effects of early life antibiotic administration on adult visceral pain sensitivity (84) and metabolism (85).

Perinatal stress models. Extensive preclinical literature has characterized the effects of perinatal stress on the adult CNS, including the HPA axis (86), and brain systems involved in emotion (63), pain modulation (87-89), and in intestinal function (87). The brain and behavioral effects of perinatal stress observed in rodent models show high translational validity for a range of human diseases, including functional GI disorders $(90,91)$ and psychiatric disorders (92) in which early adverse life events have been established as an important vulnerability factor. This extensive body of research, including molecular and epigenetic mechanisms, was generated without taking the gut microbiota into account. How- ever, more evidence has been reported for the involvement of the gut microbiota in these perinatal stressors in brain and associated behavioral changes, starting with initial reports showing that both maternal stress and maternal separation had an effect on the gut microbiota (82). Monkeys subjected to maternal separation between six and nine months of age showed gut microbiota changes characterized by shedding of lactobacilli three days following separation, with the return of normal lactobacilli levels seven days later. Adult rats that had undergone maternal separation showed altered fecal microbial composition compared with normally reared control animals (88). It remains unclear whether the reported microbiota changes following perinatal stress are simply a consequence of the well-established changes in stress reactivity and altered regional autonomic nervous system (ANS) regulation of gut motility and secretion (leading to a change in microbiota environment) or whether other factors play a role. However, in view of the reported effects of altered microbiota signaling to the brain, it is possible that an alteration in the brain/ gut microbiota/brain loop during certain developmental windows contributes to the adult phenotype of these animals.

Adult stress models. Considerable evidence supports the role for stress and its mediators in modulating the intestinal microbiota in adults (refs. 82, 93, 94, and reviewed in ref. 26). In adult mice, psychosocial stress reduced the proportion of Bacteroides but increased the proportion of Clostridia in the cecum (95). In the same study, stress-induced increases in IL-6 and chemokine (C-C motif) ligand 2 (MCP1) were observed, and these changes were correlated with certain bacterial species. Additional studies are needed to determine whether gut microbial alterations observed in preclinical studies and some patient studies with stress-sensitive GI disorders, such as IBS, result from stress-induced acceleration of regional intestinal transit, intestinal secretion, or other effects of stress on the intestinal microbiota.

When viewed together, these studies support a role of the gut microbiota in modulating emotional, nociceptive, and feeding behaviors in rodents. Comprehensive reviews of these studies, including speculation about possible human implications, have been published (2, 4, 17-19, 22, 23, 25, 26, 96-99). The intriguing preclinical results should inform the design of human studies in the future.

\section{Gut microbiota and human brain function and behavior}

In contrast to the emergence of a rich and robust preclinical literature on various aspects of microbiota-brain interactions, limited information is available from human studies. This may be due to (a) the increased complexity of studying the human microbiota, which is affected by wide variations in diet, environmental influences, sex-related differences, and genetic variation; (b) the difficulty of measuring subtle changes in human emotional and cognitive function; and (c) underlying functional and possibly structural changes in the human CNS. Gut microbial organization patterns have been associated with two clinical phenotypes. A recent study in babies with infant colic, often thought to be a risk factor for the development of IBS and anxiety disorders, showed reduced overall diversity, increased density of Proteobacteria, and decreased numbers of Bacterioides compared with healthy babies (33). A growing number of studies in IBS patients have provided evidence 


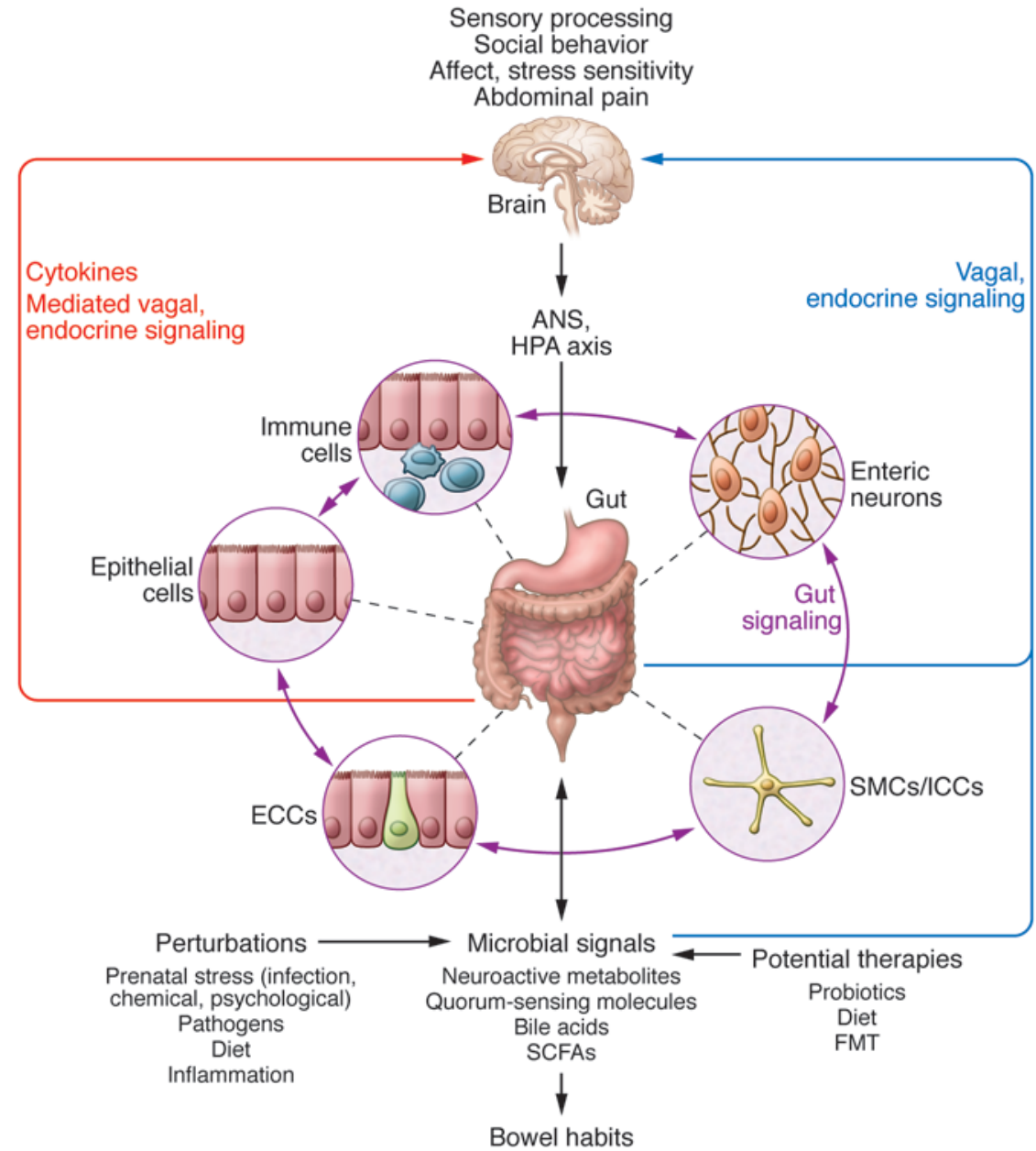

Figure 3. Bidirectional interactions within the gut microbiota/brain axis. A network of specialized target/transducer cells in the gut wall functions as an interface between the microbiota and the host lumen. In response to external and bodily demands, the brain modulates these specialized cells within this network via the branches of the ANS (sympathetic and parasympathetic/vagal efferents) and the HPA axis. Such modulation can be transient, such as in response to transient perturbations, or long lasting, such as in response to chronically altered brain output. The microbiota is in constant bidirectional communication with this interface via multiple microbial signaling pathways, and this communication is modulated in response to perturbations of the microbiota or the brain. The integrated output of the gut microbialbrain interface is transmitted back to the brain via multiple afferent signaling pathways, including endocrine (metabolites, cytokines, and microbial signaling molecules) and neurocrine (vagal and spinal afferents). While acute alterations in this interoceptive feedback can result in transient functional brain changes (GI infections), chronic alterations are associated with neuroplastic brain changes. Potential therapies aim to normalize altered microbiota signaling to the ENS and central nervous system. FMT, fecal microbial transplant; ICC, interstitial cell of Cajal. for alterations in gut microbial composition (reviewed in refs. 11, 23), even though a causal role of these microbial changes in clinical symptoms has not been established.

Effect of interventions targeting the gut microbiota. Another approach to determining the effects of the gut microbiota on brain function has been to use self-reporting measures as a proxy for changes in brain function after modulating the microbiota with probiotics. In a randomized, placebo-controlled study of healthy men and women, psychological distress and anxiety improved after taking a Lactobacillus- and Bifidobacterium-containing probiotic compared with those taking a matched control product, though another study using a different Lactobacillius probiotic failed to confirm these findings $(69,100)$. Limitations in study design, including sample size, baseline mood of the subject sample, instruments used to collect the mood symptoms, interindividual variation in terms of microbial composition, and differences between the probiotics may have accounted for the discrepancy in results. Another approach has been to use functional MRI (fMRI) to assess human brain changes in response to modulation of the gut microbiota. One study has shown that chronic ingestion of a probiotic consortium changed functional brain responses in healthy women (31). In this study, the response to an emotional face recognition task was measured with fMRI in healthy women before and after taking four weeks of active probiotic, nonfermented dairy product, or no treatment at all. The women who had ingested the probiotic had a reduced response to the emotional recognition task across a wide network of brain regions that included sensory and emotional regions. There were no differences in self-reporting of symptoms of anxiety or depression between the treatment groups; however, the fMRI alterations suggest a basic change in responsiveness to negative emotional stimuli in the environment. A second brain imaging study evaluated the effects of gut microbiota modulation via administration of a nonabsorbable antibiotic in patients with hepatic encephalopathy and mild cognitive impairment (32). Performance on a cognitive task improved, along with fMRI evidence for increased subcortical brain activity and improved fronto-parietal connectivity during the task. In another study using the same underlying disorder and antibiotic treatment, cognitive function was also improved after an eight-week treatment course, in conjunction with changes in serum metabolites presumed to be of bacterial origin (101). The mechanisms by which the brain changes in response to these experimental perturbations of the gut bacteria is not clear but may include some of the gut/brain signaling mechanisms shown in Figure 3.

\section{Bidirectional interactions of the intestinal microbiota and CNS}

The CNS modulates the GI tract and ENS via the sympathetic and parasympathetic branches of the ANS, as well as via the HPA axis. These CNS influences can affect the enteric microbi- 
ota indirectly by altering its environment and directly via a large number of signaling molecules (Figure 3 and reviewed in ref. 2). Both branches of the ANS regulate gut functions such as regional motility, secretion of acid, production of bicarbonates and mucus, maintenance of epithelial fluid, permeability of the intestine, and the mucosal immune response (Figure 3 and reviewed in ref. 102). Most of these functions, except for sympathetic- and cortisol-mediated immune regulation, are affected by sympathetic and parasympathetic influences on the circuits of the ENS. Regional and overall changes in GI transit are expected to affect the rate of delivery of nutrients (such as prebiotics, including resistant starches and certain dietary fibers) to the enteric microbiota, gas composition, and other aspects of the luminal environment (reviewed in ref. 2).

ANS modulation of the gut microbial environment. Impaired intestinal transit, caused by compromised migrating motor complexes (an ENS-generated motor pattern characteristic of the fasting state of the GI tract that is under parasympathetic modulation), is associated with an increase in microbial colonization (bacterial overgrowth) in the small intestine (103). A reduced number of giant migrating contractions in the colon has been reported in patients with slow-transit constipation (104) and might contribute to symptoms in some patients with IBS and constipation. Alternatively, accelerated intestinal transit, characterized by an increased number of giant migrating contractions, is observed in some patients with diarrheal disorders such as diarrhea-predominant IBS (105). The frequency of regular migrating motor complexes is influenced by the frequency of food intake, quality of sleep, and stress. Acute stress is associated with increased parasympathetic output to the small and large intestine and reduced vagal output to the stomach (102). Even though they have not been studied outside the setting of bacterial overgrowth, these alterations in gut transit are likely to have a major impact on the composition and organizational structure of the gut microbiota in different regions of the GI tract.

ANS-mediated modulation of mucus secretion is likely to have important effects on the size and quality of the intestinal mucus layer, an important habitat for the biofilm, where most enteric microbiota reside (106). The ANS also affects epithelial mechanisms involved in activation of the immune system by the gut. This activation can occur directly through modulation of the response of the gut immune cells (e.g., macrophages and mast cells) to luminal bacteria with antimicrobial peptides (107) or indirectly by altering access of luminal bacteria to gut immune cells. For example, several preclinical studies have demonstrated that stressful stimuli can increase the permeability of the intestinal epithelium, facilitating translocation of luminal organisms and inducing an immune response in the intestinal mucosa (108-113).

Modulation of gut microbiota by host-derived signaling molecules. In addition to CNS-induced changes in the gut environment, signaling molecules used by the host for neuronal and neuroendocrine signaling, including but not limited to catecholamines, serotonin, dynorphin, GABA, and cytokines, may also be released into the gut lumen by neurons, immune cells, and enterochromaffin cells $(98,114)$. This process is likely modulated by the CNS (115-117). Catecholamines are a particularly well-studied example of signaling molecules that allow for direct host-to-microbe signaling. Different types of stressors can increase not only local and plasma levels but also luminal levels of catecholamines such as norepinephrine in the gut $(118,119)$. Some pathogens can change their proliferative activity in response to exogenous catecholamines in vitro (120). For example, norepinephrine can stimulate proliferation of several strains of enteric pathogens (119) and increase the virulent properties of Campylobacter jejuni (121). However, the effect of catecholamines on nonpathogenic organisms and other microbial signaling molecules on gut microbiota composition and metabolic activity in healthy individuals and in disease is not known.

Microbe-to-host signaling by microbial signaling molecules. A number of signaling molecules have been identified through which the gut microbiota might communicate with host systems such as the ENS (17) and the brain (Figure 3). Quorum-sensing molecules used by microbes to communicate with each other (including metabolites and neurotransmitter homologs) are also recognized by host cells and may influence enteroendocrine cells, immune cells, and nerve endings in the gut (reviewed in ref. 2). Metabolites produced by gut microbes including SCFAs, metabolites of bile acids, and neuroactive substances such as GABA, tryptophan precursors and metabolites, serotonin, and catecholamines, including free metabolite (105) and cytokines released during the immune response to microbes (95), can signal to the host via receptors on local cells within the gut. These factors can also signal via neurocrine (afferent vagal and possibly spinal) pathways and endocrine mechanisms to targets well beyond the GI tract, including vagal afferents in the portal vein and receptors in the brain (Figure 1). A significant proportion of metabolites identified in the circulation are of gut microbial origin (122), providing the theoretical basis for a vast gut microbiota-to-brain signaling system.

Fermentable carbohydrates such as acetate, propionate, and butyrate, which enter the colon and are converted into SCFAs, are a well-studied example of microbial-derived metabolites. Primary SCFAs have a number of physiologic effects, including reduction of food intake, improvement of glucose tolerance, modulation of lymphocyte and neutrophil function, and activation of epithelial cell signaling pathways (15, 123-127). Signaling through GPCRs, as well as transport of SCFAs by SLC5A8 and the resultant physiological effects, are affected by dietary intake of fermentable fiber (128). Different types of SCFA receptors have been identified on enteroendocrine cells and on neurons of the submucosal and myenteric ganglia (129). A diet supplemented with Bifidobacterium breve was associated with increased fatty acid concentrations in the brain; however, the mechanisms underlying these effects are not known (75).

In summary, there are multiple mechanisms by which the microbiota can influence interactions between the gut and the nervous system (Figure 2). Regardless of the sequence of events leading to a state of dysbiosis in a particular disorder, alterations to the microbial community are likely to affect the bidirectional communication between the gut and brain. Such influences may occur early in life and affect the development of the nervous system, the brain's interaction with the intestine, and the HPA axis; in adults, these influences may act on fully developed circuits (reviewed in refs. 3, 17, 20, and Figure 3). Some of these signaling mechanisms 
can occur in the presence of an intact epithelium (e.g., via vagal signaling) but are likely enhanced and altered in the context of increased intestinal permeability induced by stress $(130,131)$ or mucosal inflammation (60). Further studies are needed to evaluate how alterations in these microbe-host interactions and the resulting alterations in gut-brain communications affect the brain functionally and structurally.

\section{Translational implications}

One may speculate that the evolutionarily conserved symbiotic relationship between a host and its gut microbiota developed in large part for metabolic reasons, providing the organism with additional energy from ingested food components that require microbial degradation prior to absorption by the host. The rapid functional adaptability of the gut microbiota to different diets, as well as the solid preclinical and clinical evidence for an important role of the gut microbiota in normal and pathological metabolic function and the extensive remodeling of signaling systems related to ingestive behavior and intestinal absorption in the GF mouse, is consistent with this hypothesis. From this viewpoint, the observation of robust changes in the HPA axis in GF animals could be explained primarily by metabolic reasons rather than in terms of psychological stress responsiveness. The microbiota-related signaling molecules that communicate with the host may initially have developed in the context of this metabolic challenge. It has been speculated that the gut microbiota may influence the host's digestive tract (motility, secretion) and ingestive behavior (e.g., signaling systems in the gut and the brain), assuring an optimal supply and delivery of its required nutrients $(21,54,57)$. The initial primitive gut-brain signaling system may have been greatly expanded and differentiated to the current inter-kingdom signaling system through gene transfer with host epithelial cells and development of long-distance signaling mechanisms to other brain systems that are involved in emotion regulation, cognition and memory, and pain sensitivity. Another intriguing hypothesis recently proposed by Stilling et al. posits that during evolution, microbe-brain interactions critically influenced brain evolution towards the development of the social brain (28). According to this hypothesis, epigenetic mechanisms and lateral gene transfer (132) may have played crucial roles in this process. Based on existing preclinical and clinical data, it is safe to assume that the gut microbiota form a crucial link in the bidirectional interactions between the intestine and the nervous system, and that some of the alterations that affect these interactions are likely to involve changes in the gut microbiota of patients.

Despite the initial exciting preclinical findings, skepticism is warranted when extrapolating findings to human physiology and disease. It is not known whether results obtained in very strictly controlled preclinical conditions such as GF mice are relevant to human physiology and pathophysiology. There is currently limited evidence from epidemiological or high-quality clinical studies to show major effects of the normal gut microbiota or microbiota modulation with dietary changes, prebiotics, probiotics, or antibiotics on gut-brain interactions or on brain function (i.e., affect, cognition) in healthy adult humans or in human disease. Recently published studies include data demonstrating associations between gut microbial alterations and IBS (reviewed in refs. 11, 23, 133), infant colic (5), hepatic encephalopathy (101), craving in alcohol dependence (131), depression (134), and Parkinson's disease (135). In addition, small but consistent beneficial effects of probiotic intake have been reported in IBS (23). However, clinical observations have failed to reveal major effects of transient perturbations of the gut microbiota on human behavior.

The main effect of the gut microbiota perturbations on the brain may occur at times of lower diversity and instability of the gut microbiota (infants and the elderly) (136-138) and during brain development (perinatal and infant period) (139). During the prenatal period, the developing brain is first exposed to maternal gut-derived metabolites and may be exposed to intrauterine microbes (61). During birth, the newborn's gut microbiota is shaped by the maternal vaginal (or skin) microbiota (reviewed in refs. 22, 81). Even though the possibility that pre- and postnatal influences on the microbiota can affect brain development is intriguing (Figure 2), there has not been any research in humans characterizing the effect of maternal microbiota modulation on fetal brain development and adult sequelae of such modulation. As shown in Figure 1, the human gut/brain axis fundamentally differs from the rodent axis primarily because of the great expansion of the prefrontal cortex and the frontoinsular regions, which play a major role in human emotional regulation.

Carefully designed translational and clinical studies are required to determine how alterations in these interactions begin and how they are sustained over time. These studies should include longitudinal characterization of microbiota and metabolomic profiles of large cohorts of carefully phenotyped patients (including host genetics [ref. 140], dietary habits, medication use, health status, and comorbid illness), compared with carefully matched individuals without the disease. Controlled interventional studies are also needed to test the effects of prebiotics, probiotics, antibiotics, dietary modifications, and possibly fecal microbial transplantation in patients with disorders in which altered gut microbiota-to-brain signaling has been implicated. These studies should include analyses of changes in intestinal microbiota and metabolomics profiles to correlate any effects on GI functions and symptoms with specific microbial changes. It will also be important to study infants to determine how alteration of the microbiota early in life affects brain development and the interactions between the gut and brain, and whether reagents designed to reduce dysbiosis can change these interactions.

\section{Acknowledgments}

This work was in part supported by NIH grants DK 64539 and DK 48351 (to E.A. Mayer) and AT 007137 (to K. Tillisch). The authors thank C. Liu and C. Fling for invaluable editorial assistance.

Address correspondence to: Emeran A. Mayer, Oppenheimer Center for Neurobiology of Stress, Division of Digestive Diseases, UCLA CHS 42-210, 10833 Le Conte Avenue, Los Angeles, California 90095-7378, USA. Phone: 310.206.0192; E-mail: emayer@ucla.edu. 
1. Mayer EA. Gut feelings: the emerging biology of gut-brain communication. Nat Rev Neurosci. 2011;12(8):453-466.

2. Rhee SH, Pothoulakis C, Mayer EA. Principles and clinical implications of the brain-gut-enteric microbiota axis. Nat Rev Gastroenterol Hepatol. 2009;6(5):306-314

3. Cryan JF, Dinan TG. Mind-altering microorganisms: the impact of the gut microbiota on brain and behaviour. Nat Rev Neurosci. 2012;13(10):701-712.

4. Mayer EA, Padua D, Tillisch K. Altered brain-gut axis in autism: Comorbidity or causative mechanisms? Bioessays. 2014;36(10):933-939.

5. de Vos WM, de Vos EA. Role of the intestinal microbiome in health and disease: from correlation to causation. Nutr Rev. 2012;70(suppl 1):S45-S56.

6. Park AJ, et al. Altered colonic function and microbiota profile in a mouse model of chronic depression. Neurogastroenterol Motil.2013;25(9):733-e575.

7. Amaral FA, et al. Commensal microbiota is fundamental for the development of inflammatory pain. Proc Natl Acad Sci U S A. 2008;105(6):2193-2197.

8. Frazier TH, DiBaise JK, McClain CJ. Gut microbiota, intestinal permeability, obesity-induced inflammation, and liver injury. JPEN J Parenter Enteral Nutr. 2011;35(5 suppl):14S-20S.

9. Camilleri M, Lasch K, Zhou W. Irritable bowel syndrome: methods, mechanisms, and pathophysiology. The confluence of increased permeability, inflammation, and pain in irritable bowel syndrome. Am J Physiol Gastrointest Liver Physiol. 2012;303(7):G775-G785.

10. Matricon J, et al. Review article: Associations between immune activation, intestinal permeability and the irritable bowel syndrome. Aliment Pharmacol Ther. 2012;36(11-12):1009-1031.

11. Simren $\mathrm{M}$, et al. Intestinal microbiota in functional bowel disorders: a Rome foundation report. Gut. 2013;62(1):159-176.

12. Round JL, Mazmanian SK. The gut microbiota shapes intestinal immune responses during health and disease. Nat Rev Immunol. 2009;9(5):313-323.

13. Ringel Y, Maharshak N. Intestinal microbiota and immune function in the pathogenesis of irritable bowel syndrome. Am J Physiol Gastrointest Liver Physiol. 2013;305(8):G529-G541.

14. Hughes PA, Zola H, Penttila IA, Blackshaw LA, Andrews JM, Krumbiegel D. Immune activation in irritable bowel syndrome: can neuroimmune interactions explain symptoms? Am J Gastroenterol. 2013;108(7):1066-1074.

15. Cani PD, Everard A, Duparc T. Gut microbiota, enteroendocrine functions and metabolism. Curr Opin Pharmacol. 2013;13(6):935-940.

16. Valdez-Morales EE, et al. Sensitization of peripheral sensory nerves by mediators from colonic biopsies of diarrhea-predominant irritable bowel syndrome patients: a role for PAR2. Am J Gastroenterol. 2013;108(10):1634-1643.

17. Forsythe P, Kunze WA. Voices from within: gut microbes and the CNS. Cell Mol Life Sci. 2013;70(1):55-69.

18. Dinan TG, Cryan JF. Regulation of the stress response by the gut microbiota: implications for psychoneuroendocrinology. Psychoneuroendocrinology. 2012;37(9):1369-1378.
19. Foster JA, McVey Neufeld KA. Gut-brain axis: how the microbiome influences anxiety and depression. Trends Neurosci. 2013;36(5):305-312.

20. Bercik P, Collins SM, Verdu EF. Microbes and the gut-brain axis. Neurogastroenterol Motil. 2012;24(5):405-413.

21. Alcock J, Maley CC, Aktipis CA. Is eating behavior manipulated by the gastrointestinal microbiota? Evolutionary pressures and potential mechanisms. Bioessays. 2014;36(10):940-949.

22. Stilling RM, Dinan TG, Cryan JF. Microbial genes, brain \& behaviour - epigenetic regulation of the gut-brain axis. Genes Brain Behav. 2014;13(1):69-86.

23. Mayer EA, Savidge T, Shulman RJ. Brain-gut microbiome interactions and functional bowel disorders. Gastroenterology. 2014;146(6):1500-1512.

24. Ford AC, et al. Efficacy of prebiotics, probiotics, and synbiotics in irritable bowel syndrome and chronic idiopathic constipation: systematic review and meta-analysis. Am J Gastroenterol. 2014;109(10):1547-1561.

25. Collins SM. A role for the gut microbiota in IBS. Nat Rev Gastroenterol Hepatol. 2014;11(8):497-505.

26. De Palma G, Collins SM, Bercik P, Verdu EF. The microbiota-gut-brain axis in gastrointestinal disorders: stressed bugs, stressed brain or both? JPhysiol. 2014;592(pt 14):2989-2997.

27. Dinan TG, Stanton C, Cryan JF. Psychobiotics: a novel class of psychotropic. Biol Psychiatry. 2013;74(10):720-726

28. Stilling RM, Bordenstein SR, Dinan TG, Cryan JF. Friends with social benefits: host-microbe interactions as a driver of brain evolution and development? Front Cell Infect Microbiol. 2014;4:147.

29. Reeves RR. Ciprofloxacin-induced psychosis. Ann Pharmacother. 1992;26(7-8):930-931.

30. Weis S, Karagulle D, Kornhuber J, Bayerlein K. Cotrimoxazole-induced psychosis: a case report and review of literature. Pharmacopsychiatry 2006;39(6):236-237.

31. Tillisch K, et al. Consumption of fermented milk product with probiotic modulates brain activity. Gastroenterology. 2013;144(7):1394-1401.

32. Ahluwalia V, et al. Enhancement of functional connectivity, working memory and inhibitory control on multi-modal brain MR imaging with Rifaximin in Cirrhosis: implications for the gut-liver-brain axis. Metab Brain Dis. 2014;29(4):1017-1025.

33. de Weerth C, Fuentes S, Puylaert P, de Vos WM. Intestinal microbiota of infants with colic: development and specific signatures. Pediatrics. 2013;131(2):e550-e558.

34. Rezzi S, et al. Human metabolic phenotypes link directly to specific dietary preferences in healthy individuals. JProteome Res. 2007;6(11):4469-4477.

35. Bercik $\mathrm{P}$, et al. The intestinal microbiota affect central levels of brain-derived neurotropic factor and behavior in mice. Gastroenterology. 2011;141(2):599-609.

36. Collins SM, Kassam Z, Bercik P. The adoptive transfer of behavioral phenotype via the intestinal microbiota: experimental evidence and clinical implications. Curr Opin Microbiol. 2013;16(3):240-245

37. Sudo N, et al. Postnatal microbial colonization programs the hypothalamic-pituitary-adrenal system for stress response in mice. JPhysiol. 2004;558(pt 1):263-275.

38. Clarke $\mathrm{G}$, et al. The microbiome-gut-brain axis during early life regulates the hippocampal serotonergic system in a sex-dependent manner. $\mathrm{Mol}$ Psychiatry. 2013;18(6):666-673.

39. Diaz Heijtz R, et al. Normal gut microbiota modulates brain development and behavior. Proc Natl Acad Sci U S A. 2011;108(7):3047-3052.

40. Neufeld KM, Kang N, Bienenstock J, Foster JA. Reduced anxiety-like behavior and central neurochemical change in germ-free mice. Neurogastroenterol Motil. 2011;23(3):255-264.

41. Bercik P, et al. The anxiolytic effect of Bifidobacterium longum NCC3001 involves vagal pathways for gut-brain communication. Neurogastroenterol Motil. 2011;23(12):1132-1139.

42. Bravo JA, et al. Ingestion of Lactobacillus strain regulates emotional behavior and central GABA receptor expression in a mouse via the vagus nerve. Proc Natl Acad Sci U S A. 2011;108(38):16050-16055.

43. Desbonnet L, Garrett L, Clarke G, Kiely B, Cryan JF, Dinan TG. Effects of the probiotic Bifidobacterium infantis in the maternal separation model of depression. Neuroscience. 2010;170(4):1179-1188.

44. Crumeyrolle-Arias M, et al. Absence of the gut microbiota enhances anxiety-like behavior and neuroendocrine response to acute stress in rats. Psychoneuroendocrinology. 2014;42:207-217.

45. Savignac HM, Kiely B, Dinan TG, Cryan JF. Bifidobacteria exert strain-specific effects on stress-related behavior and physiology in BALB/c mice. Neurogastroenterol Motil. 2014;26(11):1615-1627.

46. Schroeder FA, Lin CL, Crusio WE, Akbarian S. Antidepressant-like effects of the histone deacetylase inhibitor, sodium butyrate, in the mouse. Biol Psychiatry. 2007;62(1):55-64.

47. Desbonnet L, Garrett L, Clarke G, Bienenstock J, Dinan TG. The probiotic Bifidobacteria infantis: an assessment of potential antidepressant properties in the rat. J Psychiatr Res. 2008;43(2):164-174.

48. Arseneault-Breard J, et al. Combination of Lactobacillus helveticus R0052 and Bifidobacterium longum R0175 reduces post-myocardial infarction depression symptoms restores intestinal permeability in a rat model. Br J Nutr. 2012;107(12):1793-1799.

49. Ait-Belgnaoui A, et al. Lactobacillus farciminis treatment suppresses stress induced viscera hypersensitivity: a possible action through interaction with epithelial cell cytoskeleton contraction. Gut. 2006;55(8):1090-1094.

50. Eutamene H, et al. Synergy between Lactobacillus paracasei and its bacterial products to counteract stress-induced gut permeability and sensitivity increase in rats. J Nutr. 2007;137(8):1901-1907.

51. Rousseaux C, et al. Lactobacillus acidophilus modulates intestinal pain and induces opioid and cannabinoid receptors. Nat Med. 2007;13(1):35-37.

52. Ma X, Mao YK, Wang B, Huizinga JD, Bienenstock J, Kunze W. Lactobacillus reuteri ingestion prevents hyperexcitability of colonic DRG neurons induced by noxious stimuli. Am J Physiol Gastrointest Liver Physiol. 2009;296(4):G868-G875.

53. Kunze WA, et al. Lactobacillus reuteri enhances 
excitability of colonic AH neurons by inhibiting calcium-dependent potassium channel opening. JCell Mol Med. 2009;13(8B):2261-2270.

54. Duca FA, Swartz TD, Sakar Y, Covasa M. Increased oral detection, but decreased intestinal signaling for fats in mice lacking gut microbiota. PLoS One. 2012;7(6):e39748.

55. Vijay-Kumar M, et al. Metabolic syndrome and altered gut microbiota in mice lacking Toll-like receptor 5. Science. 2010;328(5975):228-231.

56. Tanida M, Yamano T, Maeda K, Okumura N, Fukushima Y, Nagai K. Effects of intraduodenal injection of Lactobacillus johnsonii La1 on renal sympathetic nerve activity blood pressure in urethane-anesthetized rats. Neurosci Lett. 2005;389(2):109-114.

57. Swartz TD, Duca FA, de Wouters T, Sakar Y, Covasa M. Up-regulation of intestinal type 1 taste receptor 3 sodium glucose luminal transporter-1 expression increased sucrose intake in mice lacking gut microbiota. Br J Nutr. 2012;107(5):621-630.

58. Desbonnet L, Clarke G, Shanahan F, Dinan TG, Cryan JF. Microbiota is essential for social development in the mouse. Mol Psychiatry. 2014;19(2):146-148.

59. de Theije CG, et al. Intestinal inflammation in a murine model of autism spectrum disorders. Brain Behav Immun. 2014;37:240-247.

60. Hsiao EY, et al. Microbiota modulate behavioral and physiological abnormalities associated with neurodevelopmental disorders. Cell. 2013;155(7):1451-1463.

61. Aagaard K, Ma J, Antony KM, Ganu R, Petrosino J, Versalovic J. The placenta harbors a unique microbiome. Sci Transl Med. 2014;6(237):237ra65.

62. Fish EW, et al. Epigenetic programming of stress responses through variations in maternal care. Ann N Y Acad Sci. 2004;1036:167-180.

63. Meaney MJ. Maternal care, gene expression, and the transmission of individual differences in stress reactivity across generations. Annu Rev Neurosci. 2001;24:1161-1192.

64. Bäckhed F, Manchester JK, Semenkovich CF, Gordon JI. Mechanisms underlying the resistance to diet-induced obesity in germ-free mice. Proc Natl Acad Sci U S A. 2007;104(3):979-984.

65. Bäckhed F, et al. The gut microbiota as an environmental factor that regulates fat storage. Proc Natl Acad Sci U S A. 2004;101(44):15718-15723.

66. Braniste $\mathrm{V}$, et al. The gut microbiota influences blood-brain barrier permeability in mice. $S c i$ Transl Med. 2014;6(263):263ra158.

67. Verdu EF, et al. Specific probiotic therapy attenuates antibiotic induced visceral hypersensitivity in mice. Gut. 2006;55(2):182-190.

68. Bercik P, et al. Chronic gastrointestinal inflammation induces anxiety-like behavior and alters central nervous system biochemistry in mice. Gastroenterology. 2010;139(6):2102-2112.

69. Messaoudi M, Violle N, Bisson JF, Desor D, Javelot $\mathrm{H}$, Rougeot C. Beneficial psychological effects of a probiotic formulation (Lactobacillus helveticus R0052 and Bifidobacterium longum R0175) in healthy human volunteers. Gut Microbes. 2011;2(4):256-261

70. Neufeld KA, Kang N, Bienenstock J, Foster JA. Effects of intestinal microbiota on anxiety-like behavior. Commun Integr Biol. 2011;4(4):492-494.

71. Davari S, Talaei SA, Alaei H, Salami M. Probiotics treatment improves diabetes-induced impairment of synaptic activity and cognitive function: behavioral and electrophysiological proofs for microbiome-gut-brain axis. Neuroscience. 2013;240:287-296.

72. Gareau MG, et al. Bacterial infection causes stress-induced memory dysfunction in mice. Gut 2011;60(3):307-317.

73. Gilbert JA, Krajmalnik-Brown R, Porazinska DL, Weiss SJ, Knight R. Toward effective probiotics for autism and other neurodevelopmental disorders. Cell. 2013;155(7):1446-1448.

74. Maes M, et al. Depression and sickness behavior are Janus-faced responses to shared inflammatory pathways. BMC Med. 2012;10:66.

75. Wall R, et al. Contrasting effects of Bifidobacterium breve NCIMB 702258 and Bifidobacterium breve DPC 6330 on the composition of murine brain fatty acids gut microbiota. Am JClin Nutr. 2012;95(5):1278-1287.

76. Nishino R, et al. Commensal microbiota modulate murine behaviors in a strictly contamination-free environment confirmed by culture-based methods. Neurogastroenterol Motil. 2013;25(6):521-528.

77. Camilleri M, Madsen K, Spiller R, Greenwood-Van Meerveld B, Verne GN. Intestinal barrier function in health and gastrointestinal disease. Neurogastroenterol Motil. 2012;24(6):503-512.

78. Julio-Pieper M, Bravo JA, Aliaga E, Gotteland M. Review article: intestinal barrier dysfunction and central nervous system disorders - a controversial association. Aliment Pharmacol Ther 2014;40(10):1187-1201.

79. Resta SC. Effects of probiotics and commensals on intestinal epithelial physiology: implications for nutrient handling. J Physiol. 2009;587(pt 17):4169-4174.

80. Ohland CL, Macnaughton WK. Probiotic bacteria and intestinal epithelial barrier function. Am J Physiol Gastrointest Liver Physiol. 2010;298(6):G807-G819.

81. Clarke G, O'Mahony SM, Dinan TG, Cryan JF. Priming for health: gut microbiota acquired in early life regulates physiology, brain and behaviour. Acta Paediatr. 2014;103(8):812-819.

82. Bailey MT, Coe CL. Maternal separation disrupts the integrity of the intestinal microflora in infant rhesus monkeys. Dev Psychobiol. 1999;35(2):146-155

83. Bailey MT, Lubach GR, Coe CL. Prenatal stress alters bacterial colonization of the gut in infant monkeys. J Pediatr Gastroenterol Nutr. 2004;38(4):414-421.

84. O'Mahony SM, et al. Disturbance of the gut microbiota in early-life selectively affects visceral pain in adulthood without impacting cognitive or anxiety-related behaviors in male rats. Neuroscience. 2014;277:885-901.

85. Cox LM, et al. Altering the intestinal microbiota during a critical developmental window has lasting metabolic consequences. Cell. 2014;158(4):705-721.

86. Ladd CO, Huot RL, Thrivikraman KV, Nemeroff CB, Plotsky PM. Long-term adaptations in glucocorticoid receptor and mineralocorticoid receptor mRNA and negative feedback on the hypothalamo-pituitary-adrenal axis following neonatal maternal separation. Biol Psychiatry. 2004;55(4):367-375.

87. Coutinho SV, et al. Neonatal maternal separation alters stress-induced responses to viscerosomatic nociceptive stimuli in rat. Am JPhysiol Gastrointest Liver Physiol. 2002;282(2):G307-G316.

88. O'Mahony SM, et al. Early life stress alters behavior, immunity, and microbiota in rats: implications for irritable bowel syndrome and psychiatric illnesses. Biol Psychiatry. 2009;65(3):263-267.

89. Schwetz I, et al. Corticotropin-releasing factor receptor 1 mediates acute delayed stress-induced visceral hyperalgesia in maternally separated Long-Evans rats. Am J Physiol Gastrointest Liver Physiol. 2005;289(4):G704-G712.

90. Mayer EA, Collins SM. Evolving pathophysiologic models of functional gastrointestinal disorders. Gastroenterology. 2002;122(7):2032-2048.

91. Mayer EA, Naliboff BD, Chang L, Coutinho SV.V. Stress and irritable bowel syndrome. Am JPhysiol Gastrointest Liver Physiol. 2001;280(4):G519-G524.

92. Heim C, Nemeroff CB. The role of childhood trauma in the neurobiology of mood and anxiety disorders: preclinical and clinical studies. Biol Psychiatry. 2001;49(12):1023-1039.

93. Bailey MT, Dowd SE, Parry NM, Galley JD, Schauer DB, Lyte M. Stressor exposure disrupts commensal microbial populations in the intestines and leads to increased colonization by Citrobacter rodentium. Infect Immun. 2010;78(4):1509-1519.

94. Tannock GW, Savage DC. Influences of dietary and environmental stress on microbial populations in the murine gastrointestinal tract. Infect Immun. 1974;9(3):591-598.

95. Bailey MT, Dowd SE, Galley JD, Hufnagle AR, Allen RG, Lyte M. Exposure to a social stressor alters the structure of the intestinal microbiota: implications for stressor-induced immunomodulation. Brain Behav Immun. 2011;25(3):397-407.

96. Collins SM, Bercik P. The relationship between intestinal microbiota and the central nervous system in normal gastrointestinal function and disease. Gastroenterology. 2009;136(6):2003-2014

97. Dinan TG, Cryan JF. Melancholic microbes: a link between gut microbiota and depression? Neurogastroenterol Motil. 2013;25(9):713-719.

98. Lyte M. Microbial endocrinology in the microbiome-gut-brain axis: how bacterial production and utilization of neurochemicals influence behavior. PLos Pathog. 2013;9(11):e1003726.

99. Bravo JA, et al. Communication between gastrointestinal bacteria and the nervous system. Curr Opin Pharmacol. 2012;12(6):667-672.

100.Benton D, Williams C, Brown A. Impact of consuming a milk drink containing a probiotic on mood and cognition. Eur JClin Nutr. 2007;61(3):355-361.

101.Bajaj JS, et al. Modulation of the metabiome by rifaximin in patients with cirrhosis and minimal hepatic encephalopathy. PLos One. 2013;8(4):e60042.

102. Mayer EA. The neurobiology of stress and gastrointestinal disease. Gut. 2000;47(6):861-869.

103. Van Felius ID, et al. Interdigestive small bowel 
motility and duodenal bacterial overgrowth in experimental acute pancreatitis. Neurogastroenterol Motil. 2003;15(3):267-276.

104.Lembo A, Camilleri M. Chronic constipation. New Engl JMed. 2003;349(14):1360-1368.

105. Chey WY, Jin HO, Lee MH, Sun SW, Lee KY. Colonic motility abnormality in patients with irritable bowel syndrome exhibiting abdominal pain and diarrhea. Am J Gastroenterol. 2001;96(5):1499-1506.

106. Macfarlane S, Dillon JF. Microbial biofilms in the human gastrointestinal tract. J Appl Microbiol. 2007;102(5):1187-1196.

107. Alonso C, et al. Maladaptive intestinal epithelial responses to life stress may predispose healthy women to gut mucosal inflammation. Gastroenterology. 2008;135(1):163-172.

108. Groot J, Bijlsma P, Van Kalkeren A, Kiliaan A, Saunders P, Perdue M. Stress-induced decrease of the intestinal barrier function. The role of muscarinic receptor activation. Ann N Y Acad Sci. 2000;915:237-246.

109. Jacob C, et al. Mast cell tryptase controls paracellular permeability of the intestine. Role of protease-activated receptor 2 and beta-arrestins. J Biol Chem. 2005;280(36):31936-31948.

110. Kiliaan AJ, et al. Stress stimulates transepithelial macromolecular uptake in rat jejunum. Am J Physiol. 1998;275(5 pt 1):G1037-G1044.

111. Soderholm JD, Yates DA, Gareau MG, Yang PC, MacQueen G, Perdue MH. Neonatal maternal separation predisposes adult rats to colonic barrier dysfunction in response to mild stress. Am J Physiol Gastrointest Liver Physiol. 2002;283(6):G1257-G1263.

112. Yates DA, Santos J, Söderholm JD, Perdue MH. Adaptation of stress-induced mucosal pathophysiology in rat colon involves opioid pathways. Am J Physiol Gastrointest Liver Physiol. 2001;281(1):G124-G128.

113. Keita AV, Soderholm JD. The intestinal barrier and its regulation by neuroimmune factors. Neurogastroenterol Motil. 2010;22(7):718-733.

114. Lyte M, Freestone PPEE. Microbial Endocrinology: Interkingdom Signaling In Health Disease. New York, New York, USA: Springer Publishers; 2010.

115. Santos J, et al. Release of mast cell mediators into the jejunum by cold pain stress in humans. Gas- troenterology. 1998;114(4):640-648.

116. Stephens RL, Tache Y. Intracisternal injection of a TRH analogue stimulates gastric luminal serotonin release in rats. Am J Physiol. 1989;256(2 pt 1):G377-G383.

117. Yang H, Stephens RL, Tache Y. TRH analogue microinjected into specific medullary nuclei stimulates gastric serotonin secretion in rats. $\mathrm{Am}$ JPhysiol. 1992;262(2 pt 1):G216-G222.

118. Alverdy J, et al. Gut-derived sepsis occurs when the right pathogen with the right virulence genes meets the right host: evidence for in vivo virulence expression in Pseudomonas aeruginosa. Ann Surg. 2000;232(4):480-489.

119. Hughes DT, Sperandio V. Inter-kingdom signalling: communication between bacteria and their hosts. Nat Rev Microbiol. 2008;6(2):111-120.

120. Lyte M. Microbial endocrinology and infectious disease in the 21st century. Trends Microbiol. 2004;12(1):14-20.

121. Cogan TA, et al. Norepinephrine increases the pathogenic potential of Campylobacter jejuni. Gut. 2007;56(8):1060-1065.

122.Wikoff WR, et al. Metabolomics analysis reveals large effects of gut microflora on mammalian blood metabolites. Proc Natl Acad Sci U S A. 2009;106(10):3698-3703.

123. Cummings JH, Pomare EW, Branch WJ, Naylor CP, Macfarlane GT. Short chain fatty acids in human large intestine, portal, hepatic and venous blood. Gut. 1987;28(10):1221-1227.

124. Smith PM, et al. The microbial metabolites, short-chain fatty acids, regulate colonic Treg cell homeostasis. Science. 2013;341(6145):569-573.

125. Vinolo MA, et al. SCFAs induce mouse neutrophil chemotaxis through the GPR 43 receptor. PLoS One. 2011;6(6):e21205.

126.Layden BT, Angueira AR, Brodsky M, Durai V, Lowe WL Jr. Short chain fatty acids and their receptors: new metabolic targets. Transl Res. 2013;161(3):131-140.

127. Nepelska M, et al. Butyrate produced by commensal bacteria potentiates phorbol esters induced AP-1 response in human intestinal epithelial cells. PLoS One. 2012;7(12):e52869.

128. Ganapathy V, Thangaraju M, Prasad PD, Martin PM, Singh N. Transporters and receptors for short-chain fatty acids as the molecular link between colonic bacteria and the host. Curr Opin Pharmacol. 2013;13(6):869-874

129. Nohr MK, et al. GPR41/FFAR3 and GPR43/ FFAR2 as cosensors for short-chain fatty acids in enteroendocrine cells vs FFAR3 in enteric neurons and FFAR2 in enteric leukocytes. Endocrinology. 2013;154(10):3552-3564.

130. Soderholm JD, Perdue MH. Stress and gastrointestinal tract. II. Stress and intestinal barrier function. Am J Physiol Gastrointest Liver Physiol. 2001;280(1):G7-G13.

131. Leclercq S, et al. Intestinal permeability, gut-bacterial dysbiosis, and behavioral markers of alcohol-dependence severity. Proc Natl Acad Sci U S A. 2014;111(42):E4485-E4493.

132. Iyer LM, Aravind L, Coon SL, Klein DC, Koonin EV. Evolution of cell-cell signaling in animals: did late horizontal gene transfer from bacteria have a role? Trends Genet. 2004;20(7):292-299.

133. Jalanka-Tuovinen J, et al. Faecal microbiota composition and host-microbe cross-talk following gastroenteritis and in postinfectious irritable bowel syndrome. Gut. 2014;63(11):1737-1745.

134. Naseribafrouei A, et al. Correlation between the human fecal microbiota and depression. Neurogastroenterol Motil. 2014;26(8):1155-1162.

135. Scheperjans F, et al. Gut microbiota are related to Parkinson's disease and clinical phenotype [published online ahead of print December 5, 2014]. Mov Disord. doi:10.1002/mds.26069.

136. Ursell LK, et al. The intestinal metabolome: an intersection between microbiota and host. Gastroenterology. 2014;146(6):1470-1476.

137. Costello EK, Lauber CL, Hamady M, Fierer N, Gordon JI, Knight R. Bacterial community variation in human body habitats across space and time. Science. 2009;326(5960):1694-1697.

138. Lozupone CA, et al. Meta-analyses of studies of the human microbiota. Genome Res. 2013;23(10):1704-1714.

139. Borre YE, O'Keeffe GW, Clarke G, Stanton C, Dinan TG, Cryan JF. Microbiota and neurodevelopmental windows: implications for brain disorders. Trends Mol Med. 2014;20(9):509-518.

140.Spor A, Koren O, Ley R. Unravelling the effects of the environment and host genotype on the gut microbiome. Nat Rev Microbiol. 2011;9(4):279-290. 